\title{
Effect of microwave sintering parameters on the physical and mechanical properties of pure Ti and blended elemental Ti alloys
}

\author{
Stella Raynova ${ }^{1, a^{*}}$, M. Ashraf Imam²,b, Hunter Taylor ${ }^{3, c}$, Fei Yang ${ }^{1, d}$, Leandro \\ Bolzoni ${ }^{1, e}$
}

${ }^{1}$ Waikato Centre for Advanced Materials, School of Engineering, The University of Waikato,
Hamilton 3240, New Zealand

${ }^{2}$ Department of Mechanical \& Aerospace Engineering, The George Washington University, Washington, DC 20052, U.S.A.

${ }^{3}$ MATSYS, Inc., 45490 Ruritan Circle, Sterling, VA 20164, USA

astella.raynova@waikato.ac.nz, bashrafimam@gwu.edu, chutaylor@vt.edu,

dfei.yang@waikato.ac.nz, eleandro@waikato.ac.nz

Keywords: Microwave sintering, blended elemental powder, titanium alloys, mechanical properties, microstructure

\begin{abstract}
Microwave sintering (MWS) was used to consolidate hydride de-hydride Ti powder and blended elemental Ti6Al4V, Ti5Fe and Ti5Al5Mo5V3Cr (Ti5553) powder mixtures. The amount of powders used to prepare the powder compacts was scaled up to 500g.The effect of the MWS conditions on the relative density, porosity distribution, microstructure and tensile properties were studied. Furthermore, uniformity in distribution of the alloying elements was checked. For most of the materials considered, a combinations of sintering temperature of $1200^{\circ} \mathrm{C}$ and $1300^{\circ} \mathrm{C}$ and holding time of 5 to 30 min resulted in significantly improved density. Nevertheless sintering temperature of at least $1300^{\circ} \mathrm{C}$ was required for pore coalescence and high tensile properties.
\end{abstract}

\section{Introduction}

Microwave energy has been successfully used in the last decades in domestic microwave ovens because of the significantly faster heating time and energy saving. The application of microwave (MW) technology in materials processing is not even close to a wide use but it in a developing stage and research shows similar advantages of reduced processing time and energy saving. Sintering practice is still one of the most used consolidation method for metal and ceramic powders where the commonly used radiation heating is a long and uneconomical process. The use of MW in the sintering practice is viable and attempts were made starting from 1970s, when MWS was used for the consolidation of ceramic powders [1]. Since then the research on MWS of ceramic powders went long way and significant progress in application and commercialization of microwave technology in ceramics processing has been made [2]. MWS of metal powders is significantly more challenging because metals are MW reflectors and heating solid metals by direct MW is impossible. Heating metal powders is proven to be challenging but not impossible as the metal powder compacts have pores acting as dielectric component and are covered with metal oxide helping microwave coupling which in turn could decrease the MW reflection [3]. Early research on MWS of metal powders such as $\mathrm{Cu}, \mathrm{Al}, \mathrm{Fe}$ and $\mathrm{Co}$ are available [4-6]. Recently research was also found on MWS of $\mathrm{Ti}, \mathrm{TiH}_{2}$ and pre-alloyed Ti6Al4V powders [7-13]. These works made a significant contribution in improving the MW furnace design, which increased the sintering efficiency and consequently proved the advantages of MWS metallic materials, such as shorter processing time, enhanced densification and improved mechanical properties. Some research on the synthesis of Ti alloys by the blended elemental (BE) approach using MW heating is available [14] but information is rather limited and not many alloy compositions were studied.

This work focuses on investigating the effect of the temperature on the level of densification, homogenization of the alloying elements, microstructure and tensile properties of pure $\mathrm{Ti}$ and Ti6Al4V, Ti5Fe and Ti5553 powder blends green compacts consolidated by MWS. The size of the powder billets are significantly larger compare to those reported in the literature. 


\section{Experimental Method}

Ti powder produced by hydrogenation de-hydrogenation (HDH) method was used as base material for MWS. To make the BE alloy compositions, Ti was mixed with the appropriate ratio of Al60V40 master alloy, elemental Fe powder or mixture of Cr70Al30 and Mo40V40A120 master alloy powders to make, respectively, the Ti6A14V, Ti5Fe and Ti5553 alloys. The powder particle sizes and oxygen content of the starting powders are shown in Table 1.

Table 1. Characteristics of the raw materials used in this study.

\begin{tabular}{|c|c|c|c|c|}
\hline Powder composition & Ti- HDH & Fe- carbonyl & Cr70Al30 & Mo40V40Al20 \\
\hline Size [mesh] & -200 & -1200 & -200 & -200 \\
\hline Oxygen [wt.\%] & 0.23 & 0.32 & 0.25 & 0.20 \\
\hline
\end{tabular}

The powder mixtures were blended in a V-mixer and 500g were used to prepare each green compact. The powder from each composition was compacted into cylindrical billets with diameter of $56 \mathrm{~mm}$ using warm compaction $\left(230^{\circ} \mathrm{C}\right)$ and uniaxial pressure of $430 \mathrm{MPa}$.

MWS was carried out in a modified version of equipment described elsewhere $[9,15]$. To intensify the MWS, the powder compacts were embedded with susceptors, made of $19 \times 19 \times 50 \mathrm{~mm} 50 \%$ yttrium stabilized zirconia 50\% SiC bricks. Approximately 25 were used for each powder compact. Sintering was done in vacuum. The temperature was measured with a 2 colour pyrometer IMPAC IGAR $12-10$ with ranger of $450^{\circ} \mathrm{C}-1700^{\circ} \mathrm{C}$. Three temperature ranges (Range 1 to Range 3) between $1200^{\circ} \mathrm{C}$ and $1400^{\circ} \mathrm{C}$ were used for the MWS. The holding time at maximum temperature was up to 30min. The detailed process parameters for MWS are given in Table 2. It can be noticed that the accurate control of the sintering parameters proved challenging and slight variation with respect to the targeted values of the manufacturing conditions were actually used to sinter the materials.

Table 2. Details of the processing parameters used to MWS the different Ti alloys.

\begin{tabular}{|c|c|c|c|c|c|c|}
\hline \multirow{2}{*}{ Alloy } & \multicolumn{2}{|c|}{ TR1 parameters } & \multicolumn{2}{c|}{ TR2 parameters } & \multicolumn{2}{c|}{ TR3 parameters } \\
\cline { 2 - 7 } & Temp $\left[{ }^{\circ} \mathrm{C}\right]$ & Time [min] & Temp $\left[{ }^{\circ} \mathrm{C}\right]$ & Time [min] & Temp $\left[{ }^{\circ} \mathrm{C}\right]$ & Time [min] \\
\hline $\mathrm{Ti}$ & 1195 & 5 & 1275 & 17 & 1385 & 22 \\
\hline Ti6Al4V & 1185 & 12 & 1300 & 32 & 1300 & 12 \\
\hline Ti5Fe & 1170 & 3 & 1300 & 22 & 1390 & 30 \\
\hline Ti5553 & 1190 & 7 & 1300 & 30 & 1350 & 31 \\
\hline $\begin{array}{c}\text { Average } \\
\text { heating rate } \\
{\left[{ }^{\circ} \mathrm{C} / \text { min] }\right.}\end{array}$ & \multicolumn{2}{|c|}{32.0} & & 31.5 & & 28.2 \\
\hline
\end{tabular}

The density of the green samples was obtained by measuring volume using linear dimensions and weight of the green billets whereas the density of the sintered samples was obtained by the Archimedes method. Porosity distribution and microstructure analysis were performed using scanning electron microscope (SEM) which was also used for semi-quantitative EDS elemental analysis. Dog-bone tensile samples were cut from the sintered billets with an EDM equipment. Tensile properties of the sintered samples were tested on a none-standard tensile test sample with a 
rectangular shape with cross section of $2 \times 2 \mathrm{~mm}^{2}$ and $20 \mathrm{~mm}$ length. The tests were done at room temperature using an Instron 33R4204 universal testing machine with a load cell of $5 \mathrm{kN}$ and cross head speed of $0.1 \mathrm{~mm} / \mathrm{min}$. An extensometer with gauge length of $10 \mathrm{~mm}$ was used to measure the tensile strain. At least three measurements were obtained of each of the property analysed.

\section{Results and Discussion}

As previously mentioned, MWS process parameters such as maximum sintering temperature and holding time at temperature (Table 1), could not be controlled accurately. Nevertheless, the average heating rates are fairly uniform within the sintering temperature variance. The values are between 28.2 and $32.0^{\circ} \mathrm{C} / \mathrm{min}$, which is also significantly higher with respect to the commonly used $10^{\circ} \mathrm{C} / \mathrm{min}$ of high vacuum sintering. Moreover the heating rates are similar to these found in the literature when MWS was used for consolidation of Ti based powder compact with weight in a range of $50 \mathrm{~g}$ [14].

The results of density measurements (Figure 1) show significant improvement of the densities as a result of the MWS for all processing conditions. Generally, the sintering temperature and holding time do not have a remarkable effect on the sintered density within the samples with similar composition. The densities obtained for Ti and Ti6Al4V alloy are fairly similar, in a range of $94 \%$ to $96 \%$ of their theoretical density, and are comparable to those found in literature for similar materials and MWS conditions although smaller size samples were processed in previous studies $[14,16]$. The Ti5Fe alloy shows slightly lower density of $92 \%$ to $94 \%$ and the lowest sintered density is achieved for the T5553 alloy, around $87 \%$.

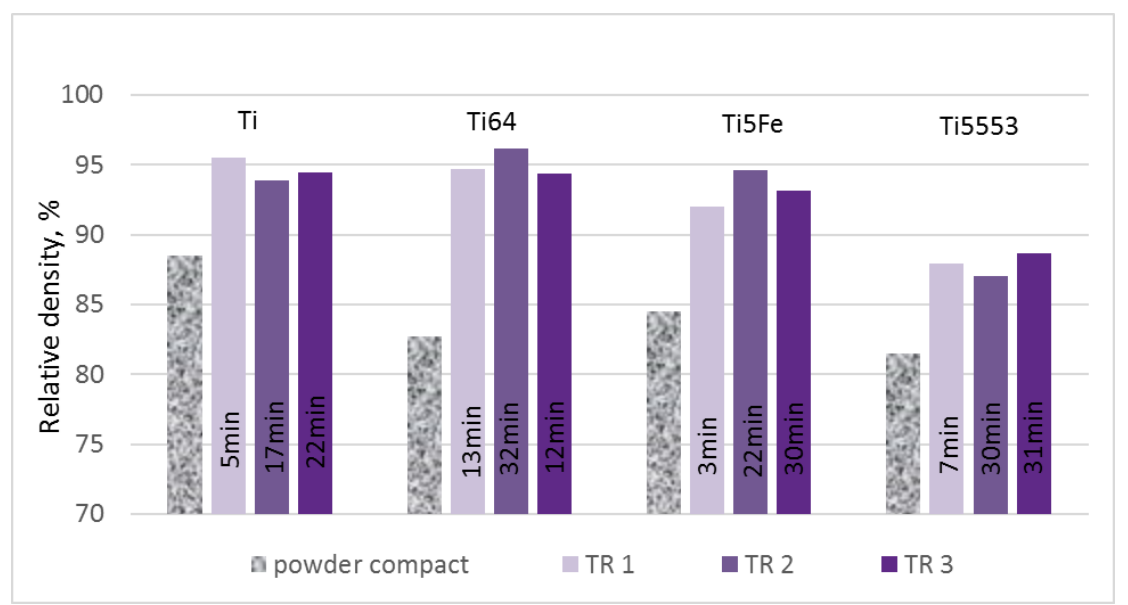

Figure 1. Variation of the relative density with the sintering parameters for MWS Ti, Ti6Al4V, Ti5Fe and Ti5553 alloys.

Analysis of the porosity distribution relates good with the results of the sintered densities. Images of the porosity distribution for MWS conditions TR1 and TR2 are shown in Figure 2. For Ti, Ti6Al4V and Ti5Fe alloys, it is found that after 3 to 5 min sintering at $1200^{\circ} \mathrm{C}$ the materials are already in the final stage of sintering leading to closed porosity as shown in Figures 2a, c and e. The pores morphology has smooth edges but still irregular shape. Further increase of the sintering temperatures to $1300^{\circ} \mathrm{C}$ and $1400^{\circ} \mathrm{C}$ result in the reduction of the pore size whereas the shape is predominantly spherical as shown in Figures $2 \mathrm{~b}, \mathrm{~d}$ and $\mathrm{f}$. The size and morphology of the pores found in the MW sintered Ti and Ti6Al4 samples is comparable to those reported in study [16], where similar or lower temperature was used. These results showed that the efficiency of the MWS is not largely dependent of the powder compact size. Also, the porosity distribution of 30min MWS $\mathrm{Ti}$ and Ti6Al4V is comparable to these of the $2 \mathrm{~h}$ vacuum sintered Ti presented in same study [16], clearly showing the advantage of the MWS of significantly reduced processing time.

In the case of the Ti5553 alloy, the samples sintered at $1200^{\circ} \mathrm{C}$ (Figure $2 \mathrm{~g}$ ) has areas with interconnected porosity (i.e. pore network) indicating that the material only reached the initial stage of sintering where development of interparticle necking occurs. Therefore, some powder particle 
boundaries are still visible. An increase of the temperature and holding time for this alloy composition results in structures with significantly smaller pore network and some closed porosity started to form but still mainly irregular in shape (Figure $2 \mathrm{~h}$ ). Except

The presence of alloying elements such as Mo with low diffusivity in Ti [17] slows down the overall mass transfer during sintering and slower the densification influencing the achievement of a fully homogeneous distribution of the alloying elements. EDS analysis indicates that after sintering at $1200^{\circ} \mathrm{C}$ there are still many Mo- and V-rich regions (Figure 3), confirming the slower diffusivity of Mo in the Ti lattice. V was alloyed with Mo in the starting master alloy and this affected its diffusion too. The other two alloying components, $\mathrm{Cr}$ and $\mathrm{Al}$ added in the form of $\mathrm{Cr}-\mathrm{Al}$ master alloy, show fairly uniform distribution in the Ti matrix.
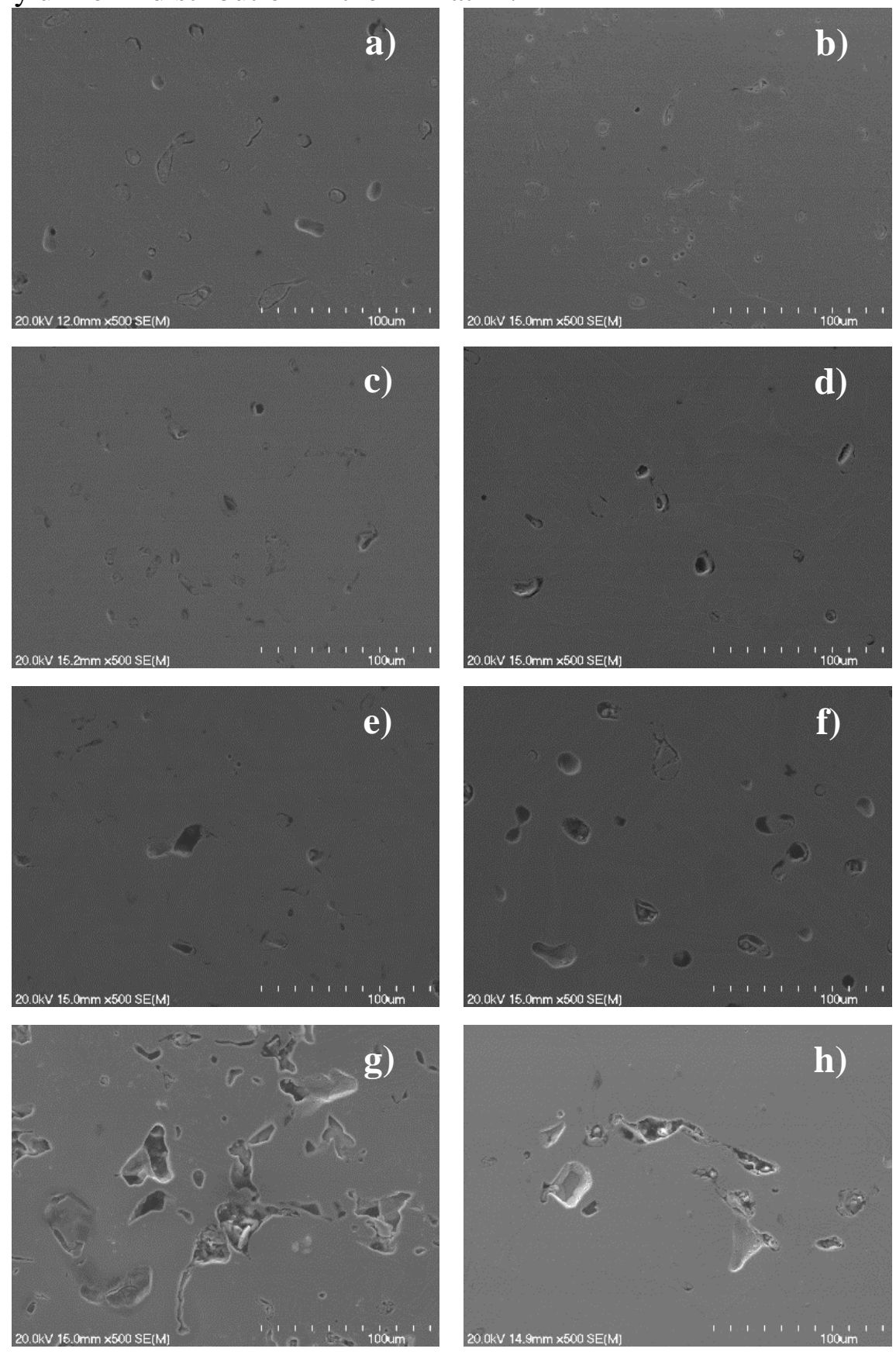

Figure 2. Porosity distribution of a) and b) Ti, c) and d) Ti6Al4V, e) and f) Ti5Fe and g) and h) Ti5553alloys MWS using TR1 and TR2 conditions, respectively.

Mo- and V-rich regions are not observed in the samples sintered at higher temperatures and longer sintering times. EDS analysis confirmed consistent distribution of the alloying elements for the other two alloy compositions for all sintering conditions. The EDS results are evidence that MWS 
can be used for sintering of blended elemental PM Ti alloys. A combination of temperature of $1200^{\circ} \mathrm{C}$ and sintering time of $3 \mathrm{~min}$ to $13 \mathrm{~min}$ allowed complete diffusion of all alloying elements in the Ti6Al4V and Ti5Fe alloys. Conversely, a higher temperature and longer sintering time of 30 min is needed to complete the homogenization of Mo and V in the Ti5553 alloy.

Figure 4 shows representative examples of microstructures developed during MWS. All material compositions showed lamellar microstructure. In $\mathrm{Ti}$, the lamellae are consisting of $\alpha$-phase situated in primary $\alpha$-phase matrix (Figure 4a) and are significantly coarser compared to those in the alloy samples. The microstructure of Ti6Al4V alloy consists of fine $\alpha$-phase lamellae outlined with $\beta$ phase typical of $\alpha+\beta$ titanium alloys slowed cooled from a processing temperature above their $\beta$ transus temperature (Figure $4 b$ ).

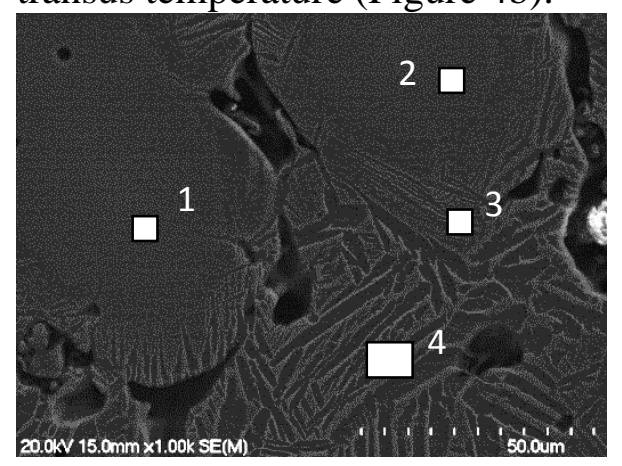

\begin{tabular}{lccccc} 
& Al-K & Ti-K & $\boldsymbol{V}-\boldsymbol{K}$ & $\boldsymbol{C r}-\boldsymbol{K}$ & Mo- $\boldsymbol{L}$ \\
\hline Ppt1 & 3.91 & 73.14 & 10.75 & 1.24 & 10.96 \\
Pt2 & 3.36 & 65.69 & 15.74 & 0.77 & 14.44 \\
Pt3 & 4.07 & 82.85 & 6.67 & 1.27 & 5.14 \\
Pt4 & 3.53 & 83.07 & 4.92 & 3.75 & 4.73 \\
\hline
\end{tabular}

Figure 3. EDS composition analysis of the Ti5553 alloy sintered at condition TR 1.
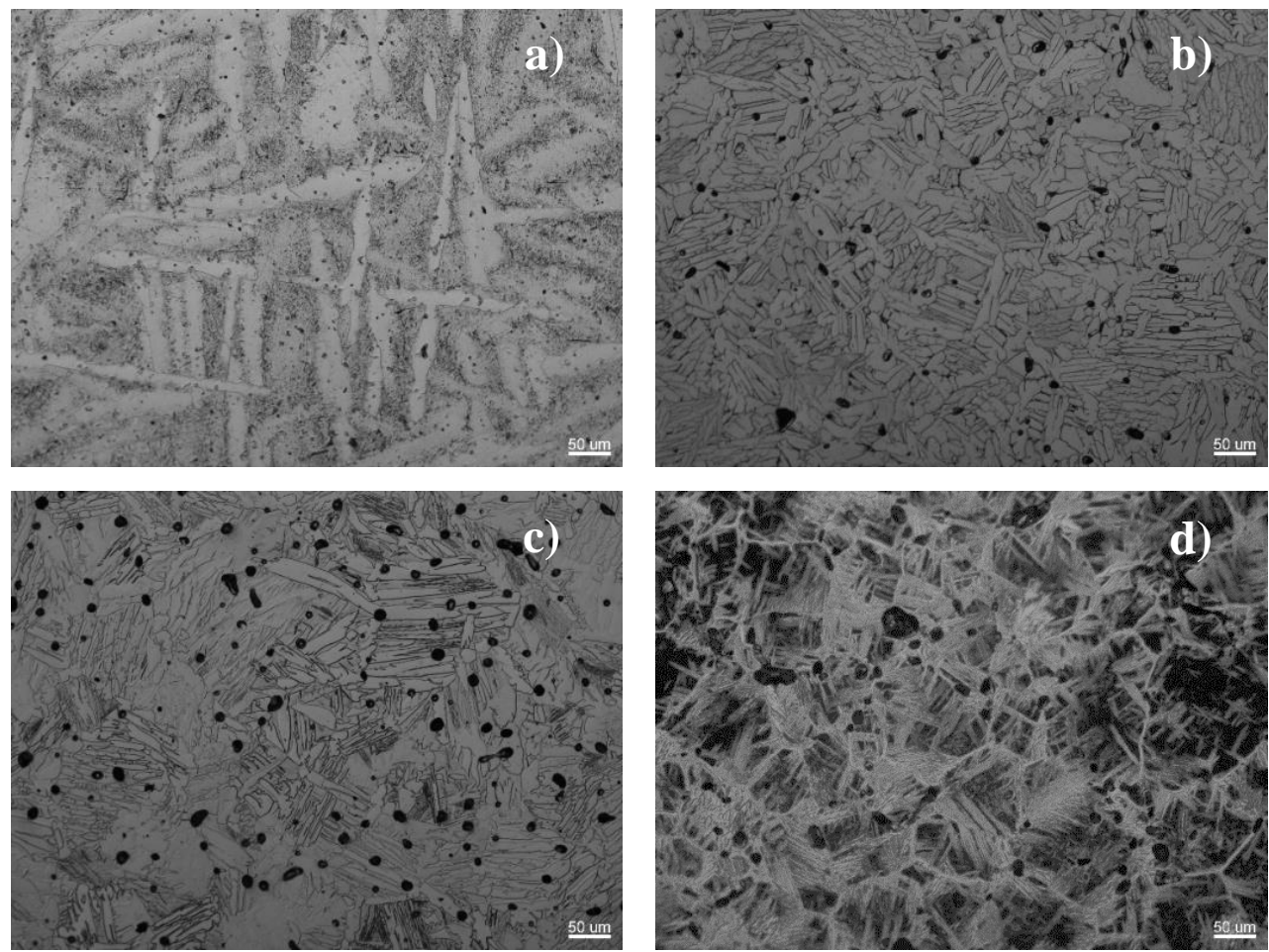

Figure 4. Microstructure of a) Ti, b) Ti6Al4V, c) Ti5Fe and d) Ti5553 alloys MWS using TR2 conditions.

Similar to Ti6Al4V alloy, the microstructure of the Ti5Fe alloy consists of $\alpha$-phase lamellae, but the size of the lamellae is not uniform (Figure 4c). From EDS analysis, the $\alpha$-phase lamellae are situated in a $\beta$-phase matrix. Considering that $\mathrm{Fe}$ is a $\beta$-phase stabilizer and the $\alpha+\beta$ phase region is in a wider temperature range according to the Ti-Fe phase diagram [18], more $\beta$-phase is retained during the cooling after sintering. The continuous nucleation and growth of $\alpha$-phase during cooling from sintering temperature to the temperature of approximately $600^{\circ} \mathrm{C}$, where the $\beta$ - to $\alpha$-phase transformation ends, lead to formation of $\alpha$-phase with different sizes, morphology and orientations. 
After MWS, the microstructure of Ti5553 alloy consists of large equiaxed grains. Inside each grain there are colonies of very thin unidirectional orientated lamellae as shown in Figure 4d.

The variation of the tensile properties is consistent with the level of densification and the microstructure developed as a result of the sintering step demonstrated via the trend for the ultimate tensile strength (UTS) of the different alloys (Figure 6). Pure Ti samples show UTS of 440MPa to over $500 \mathrm{MPa}$ at the different sintering temperatures, confirming that significant consolidation is already achieved with the lower temperature range (TR1). Ti6Al4V alloy shows UTS of 880MPa for the lower sintering temperature (TR1), while MWS at intermediate temperature (TR2) permitted to reach UTS of $1000 \mathrm{MPa}$. The values of UTS for Ti and Ti6Al4V, MWS samples are comparable to those of PM Grade $4 \mathrm{Ti}$ [19] and to those of MWS Ti using similar temperatures [14].

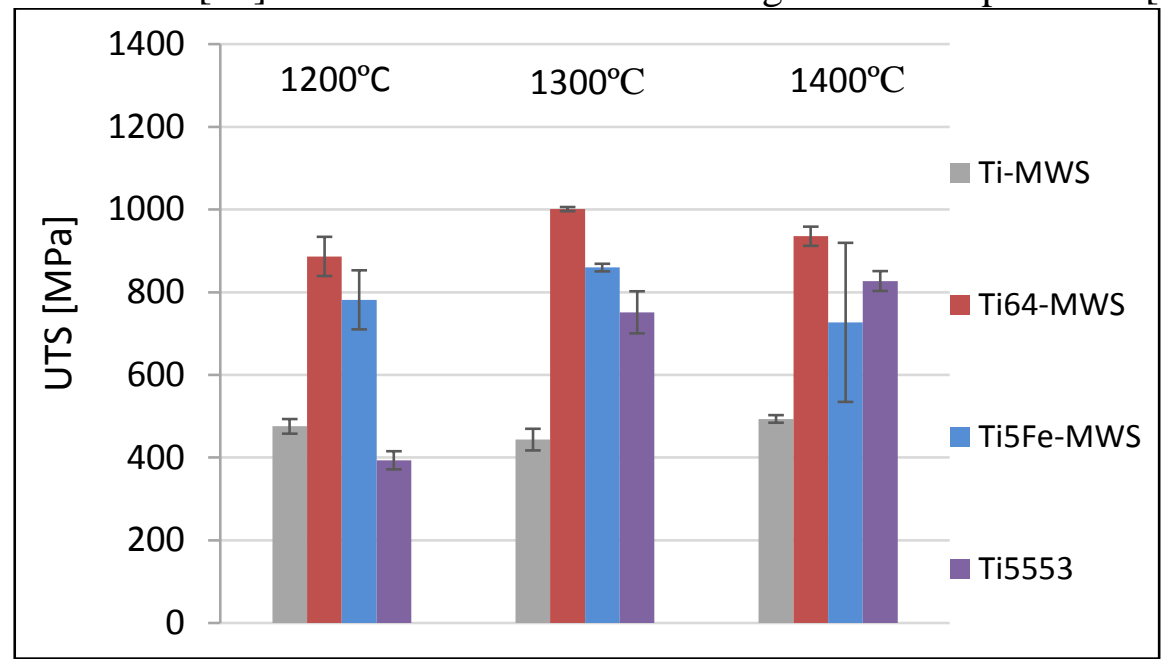

Figure 5. Variation of ultimate tensile strength with the sintering parameters of MWS Ti, Ti6Al4V, Ti5Fe and Ti5553 alloys.

Ti5Fe alloy sintered at lower temperature range (TR1) has UTS in the range of $800 \mathrm{MPa}$ when sintered at $1200^{\circ} \mathrm{C}$ followed by an increase to $860 \mathrm{MPa}$ at $1300^{\circ} \mathrm{C}$ and a final decrement of the tensile strength with further increase of the sintering temperature. In the case of the Ti5553 alloy, low tensile strength is achieved at lower sintering temperature of $1200^{\circ} \mathrm{C}$ due to the presence of large amount of interconnected pores as well as the uncompleted diffusion of Mo-V master alloy particles. Increasing the sintering temperature leads to higher UTS to up to $800 \mathrm{MPa}$, but the values are lower in comparison to its wrought counterpart.

\section{Conclusions}

Microwave sintering (MWS) was used for consolidation of pure HDH Ti powder and blended elemental powder mixtures of nominal compositions of Ti6A14V, Ti5Fe and Ti5553 alloys. Based on the study performed, the following conclusions can be drawn:

1. It is clear that MWS can be used to process powder $\mathrm{Ti}$ alloys reducing the total manufacturing time compared to the conventional vacuum sintering;

2. Combinations of sintering temperature of $1200^{\circ} \mathrm{C}$ and $13 \mathrm{~min}$ are enough to complete the dissolution and homogenization of Fe and 60Al-40V powder particles in the Ti matrix;

3. Under the conditions tested, significant improvements in densification are observed for pure Ti, Ti6Al4V and Ti5-Fe as evident by the porosity distribution and closed porosity. However, higher temperatures and longer dwell times are generally needed to achieve tensile properties comparable to those of the corresponding vacuum sintered materials;

4. Densification and homogenisation of heavily alloyed Ti alloys such as Ti5553 requires higher temperature and longer sintering times with respect to the other compositions studied. After sintering at $1200^{\circ} \mathrm{C}$, some undissolved master alloys particles are still present. The microstructures show significant amount of pore network even after sintering at $1400^{\circ} \mathrm{C}$. Consequently this alloy has lower tensile strength among the Ti alloys studied; 
5. MWS can be used for the consolidation of large Ti based powder compacts of up to $500 \mathrm{~g}$. By comparison, the data available in the literature show that in most of the cases the size of the powder compact does not significantly affect the heating rate, level of densification and tensile strength of the sintered alloys.

\section{Acknowledgements}

The authors would like to acknowledge the financial support from New Zealand Ministry of Business, Innovation and Employment (MBIE) through the TiTeNZ (Titanium Technologies New Zealand) UOWX1402 research contract. L. Bolzoni would also like to acknowledge the financial support from the University of Waikato via the Strategic Investment Funding scheme.

\section{Reference}

[1] M. Oghbaei, O. Mirzaee, Microwave versus conventional sintering: A review of fundamentals, advantages and applications, Journal of Alloys and Compounds 494(1-2) (2010) 175-89.

[2] V.G. Karayannis, Microwave sintering of ceramic materials, 20th Innovative Manufacturing Engineering and Energy Conference (IManEE 2016), 23-25 Sept. 2016, IOP Publishing, UK, 2016, p. 012068 (6 pp.).

[3] D. Agrawal, Microwave sintering, brazing and melting of metallic materials, Sohn International Symposium. Advanced Processing of Metals and Materials. Proceedings of the International Symposium. New, Improved and Existing Technologies: Non-Ferrous Materials Extraction and Processing, 27-31 Aug. 2006, TMS (Minerals, Metals \&amp; Materials Society), Warrendale, PA, USA, 2006, pp. 183-92.

[4] K. Saitou, Microwave sintering of iron, cobalt, nickel, copper and stainless steel powders, Scripta Materialia 54(5) (2006) 875-879.

[5] S. Gedevanishvili, D. Agrawal, R. Roy, Microwave combustion synthesis and sintering of intermetallics and alloys, Journal of Materials Science Letters 18(9) (1999) 665-8.

[6] R.M. Anklekar, D.K. Agrawal, R. Roy, Microwave sintering and mechanical properties of PM copper steel, Powder Metallurgy 44(4) (2001) 355-362.

[7] S. Luo, C.J. Bettles, M. Yan, G.B. Schaffer, M. Qian, Microwave sintering of titanium, Symposium on CostAffordable Titanium III, TMS 2010, February 12, 2010 - February 14, 2010, Trans Tech Publications Ltd, New Orleans, LA, United states, 2010, pp. 141-147.

[8] R.W. Bruce, A.W. Fliflet, H.E. Huey, C. Stephenson, M.A. Imam, Microwave sintering and melting of titanium powder for low-cost processing, TMS 2010 Spring Symposium on Cost-Affordable Titanium III, February 14, 2010 - February 18, 2010, Trans Tech Publications Ltd, Seattle, WA, United states, 2010, pp. 131-140.

[9] A.M. Imam, J. Feng, B.Y. Rock, A.W. Fliflet, Processing of titanium and its alloys by microwave energy, Advanced Materials Research 1019 (2014) 11-18.

[10] A.W. Fliflet, S.L. Miller, M.A. Imam, Evaluation of microwave-sintered titanium and titanium alloy powder compacts, Int. Symposia on Innovative Processing and Synthesis of Ceramics, Glasses and Composites, Advances in Ceramic Matrix Composites and Microwave Processing of Materials, Held During the Materials Sci. and Technol. 2011 Conf. and Exhibition, MS and T'11, October 16, 2011 - October 20, 2011, American Ceramic Society, Columbus, OH, United states, 2012, pp. 83-92.

[11] S.D. Luo, Y.F. Yang, G.B. Schaffer, M. Qian, Novel fabrication of titanium by pure microwave radiation of titanium hydride powder, Scripta Materialia 69(1) (2013) 69-72.

[12] A.M. Imam, F.H. Froes, R.G. Reddy, Cost effective developments for fabrication of titanium components, Key Engineering Materials 551 (2013) 3-10.

[13] Y.Y. Sun, S.D. Luo, Y. Ya Feng, J.F. Sun, M. Qian, A Detailed Experimental Assessment of Microwave Heating of Titanium Hydride Powder, Key Engineering Materials 704 (2016) 388-99.

[14] S.D. Luo, C.L. Guan, Y.F. Yang, G.B. Schaffer, M. Qian, Microwave Heating, Isothermal Sintering, and Mechanical Properties of Powder Metallurgy Titanium and Titanium Alloys, Metallurgical and Materials Transactions A 44(4) (2013) 1842-51.

[15] A.M. Imam, A.W. Fliflet, Sintering of metal and alloy powders by microwave/ millimeter-wave heating, US 2012/0051962 A1, 2012.

[16] S.D. Luo, M. Yan, G.B. Schaffer, M. Qian, Sintering of Titanium in Vacuum by Microwave Radiation, Metallurgical and Materials Transactions A 42A (2011) 2466-74. 
[17] A. Carman, L.C. Zhang, O.M. Ivasishin, D.G. Savvakin, M.V. Matviychuk, E.V. Pereloma, Role of alloying elements in microstructure evolution and alloying elements behaviour during sintering of a near- titanium alloy, Materials Science and Engineering: A 528(3) (2011) 1686-1693.

[18] L.S. Murray, Ti phase diagrams, ASM Metal Handbook Vol.31992, pp. 1741-1770.

[19] ASTM, ASTM B988- 13 Standard Specification for Powder Metallurgy (PM) Titanium and Titanium Alloy Structural Components. 